\title{
Effects of Interruptions on Consumer Online Decision Processes
}

\author{
Lan Xia and D. Sudharshan \\ Department of Business Administration \\ University of Illinois at Urbana-Champaign
}

\begin{abstract}
The growth of e-commerce and its attendantnew technologyfeatures has increasedinteractivity in consumer information processing and decision-makingprocesses. The pull and push of information can be both more personalized and more commonly used. The ease of pushing information may lead to interruptions in consumer information processing that are more pronounced than those experienced in non-Internetenvironments. Our study investigated the impact of interruption frequency, timing, and content and the moderating effects of consumer knowledge, control, and goal type on time spent on the decision task as well as satisfaction with the decision process and the choice. Our results show that the right configurationof interruptionsmay lead to increased online viewing time, whereas ill-designed interruptions may be detrimental.
\end{abstract}

The Internet provides an interactive information search and decision environment for consumers. Interactive features such as banner ads, pop-up windows, and intelligent agents that make purchase recommendations to consumers (e.g., collaborative filtering) are becoming more popular and are frequently used by marketers to attract attention and to promote sales. Such interactive features increase the communication between marketers and consumers and make it easier for marketers to push information to consumers over and beyond the information for which they actively search. However, these interactive features may impose interruptions to the natural cognitive flow of consumers and may further influence their decision performance and satisfaction.

Although recognized as an important construct in consumer decision models (Bettman, 1979), interruptions have not been widely studied. This is perhaps at least partially due to the difficulty in unobtrusively measuring consumer reactions to interruptions. The Internet decision environment makes interruptions to information processing more salient and behavioral responses to them less obtrusively measurable. Our study investigated how consumers respond to interruptions and the influence of interruptions on decision task performance and satisfaction. Results show that when used carefully, interruptions can be effective tools for marketers to attract consumers' attention. However, the effects of interruptions depend on the characteristics of interruptions, types of processing goals and perceived control over interruptions as well as on the individual differences of consumers.

Requests for reprints should be sent to Lan Xia, Department of Business Administration, University of Illinois at Urbana-Champaign. E-mail: lanxia@uiuc.edu

\section{REVIEW OF RELEVANT RESEARCH}

Consumer decision making is a process of information processing (Bettman, 1979; Howard \& Sheth, 1969). The specific process used varies across individuals, decisions, and contexts. We are concerned here with a decision-making scenario in which the customer is using the World Wide Web for making a purchase decision. In such scenarios, customers are often interrupted by messages or information that are pushed to them without being volitionally requested or sought for. Consumer decision making is constructive in nature (Bettman, Luce, \& Payne, 1998) and so must change with interruptions. Our objective is to study the impact of such interruptions on the decision processes. A brief review of the literature on interruption characteristics, moderating factors, and performance measures follows.

\section{The Constructive Nature of Consumer Decision Making}

Consumer decision processes are constructed by the decision makers themselves (Bettman et al., 1998) and by the context of the particular external environments (e.g., information presentation format, time pressure) in which the decisions are made (Bettman, 1988; Bettman, Johnson, Luce, \& Payne, 1993; Bettman \& Kakkar, 1977; Coupey, 1994; Payne, 1982). The shopping/decision-making environment of the Internet has changed the amount, type, and format of information available to consumers (Alba et al., 1997; Bakos, 1997). The electronic environment also provides tools for decision analysis, information storage, and information search and analysis. Thus, this environment could have a profound 
effect on how customers construct their decision-making processes to adjust appropriately to the new decision-making environment. In addition, one aspect of the Internet environment that could play a major role in influencing decision-making processes is information push. That is, advertising and other messages can be forced on an already small field of view (i.e., the monitor screen) and, thus, potentially cause a serious interruption to an ongoing decision process. Although interruptions occur in conventional shopping situations as well, it may be more exaggerated in the context of the Internet because of consumer attention on a small field of view and because the consumer may have greater volitional control in turning it off. Therefore, we argue that interruptions in the context of the Internet may significantly influence the construction of consumers' preferences and decision processes (Mandel \& Johnson, 1999).

\section{Influence of Interruptions on Task Performance}

Interruptions have been mainly studied in the context of organizational settings in which the employees' main tasks were interrupted by secondary tasks such as phone calls. Interruption has been defined as "an externally generated randomly occurring, discrete event that breaks continuity of cognitive focus on a primary task" (Coraggio, 1990, p. 12). This definition emphasizes the externality and randomness nature of interruption. Interruptions are generated by other people, machines, or events and are out of the control of the individual in question. The participant cannot control the timing of interruptions. In empirical tests, an interruption has often been operationalized as a secondary task to which workers have to pay attention (e.g., a telephone call) during the process of a main task. The impact of interruptions on task performance (e.g., time and accuracy) has been measured to assess the influence of such interruptions.

Research in psychology and organization behavior has shown that interruptions have a moderating influence on cognitive process and decision performance. They increase frustration and lead to inconsistent performance (Baron, Baron, \& Miller, 1973). Interruptions increase time to perform the primary task because extra time is necessary to backtrack and recover from the interruptions (Laird, Laird, $\&$ Fruehling, 1983). Norman and Bobrow (1975) also suggested that interruptions are severe attentional distractions that place greater demands on cognitive processing resources than the available capacity can handle. In summary, interruptions create attention overload and increase the level of stress and arousal. Interestingly, research has shown that interruptions have an inverted-U-shape effect on performance. A moderate level of interruptions facilitates the main task, whereas a high level of interruptions impedes performance on the main task (Yerkes \& Dodson, 1980). In terms of decision making, a moderate level of interruptions induces more effort spent on the task, whereas severe interruptions may encourage decision makers to use heuristics or other strategies to simplify the task, which may lead to lower decision accuracy. Besides, interruptions interact with task complexity. They have a greater facilitating effect on simple tasks than on complex tasks. Performance on simple tasks can withstand a higher level of arousal than that on complex tasks because a larger number of information cues are to be attended to in performing complex tasks.

Various characteristics of interruptions have been examined in the organizational behavior literature. Speier (1996) suggested that each interruption has its cognitive characteristics and social characteristics. The cognitive characteristics are those that are related to cognitivecapacity and that influenceinformation processing. They include frequency, duration, content, complexity, and timing. In the context of consumer decision making, an interruption can be described by how frequently it occurs, how long it takes to handle, how complex it is, whetherit is related to the current task, and at what consumerdecision stage it occurs. Social characteristics are factors that may induce variations in perceptions of interruptions. They include the form of the interruption, the source or generator of the interruption, and social expectations. Different forms of an interruption(e.g., side window vs. replacement window; email message vs. video conferencing) may elicit different responses (e.g., immediate action vs. delayed responses). Further, consumers' expectations and attitudes toward the perceived source of interruption may also influence their responses. Definitions of various characteristics of interruption from the literature and their counterparts in the study of online consumer decision processes are presented in Table 1.

\section{Interruptions in Consumer Decision Processes}

During decision processes, consumers usually have to pay attention involuntarily to some events or information (Bettman, 1979). These events or information that they have to pay attention to involuntarily are termed interruptions. Such events or information (or interruptions) are categorized into three categories: environmental events that depart from expectations, physiological events (e.g., noise), and cognitive events (e.g., new alternatives). Bettman suggested that responses to interruptions are guided by scanner ${ }^{1}$ and interrupt mechanisms ${ }^{2}$ that function at each step of the decision processes and guide the responses to interruptions. The two main effects of interruptions are (a) an increase in physiologicalactivity, such as arousal, and (b) a reassessment of the current goal hierarchy, which may lead to its modification. Although the importance of interruptions has been recognized, the ef-

\footnotetext{
${ }^{1}$ A scanner is a system, which notices what happens in the environment.

${ }^{2} \mathrm{An}$ interrupt system is a system for stopping what one is currently doing.
} 
TABLE 1

Characteristics of Interruption and Its Influence

Cognitive characteristics

Frequency

Duration

Content

Complexity

Timing

Social characteristics

Form of interruption

Generator of interruption

Social expectations
Frequency is the number of interruptions that occur during a specific task. A moderate level of interruption may motivate the task performer but increased interruptions have a deleterious effect.

Duration is the overall length of time needed to respond to the interruption. Longer duration leads to more time to recover from interruptions.

Content of interruption refers to the similarity between the interruption task and the primary task in terms of cognitive processing requirements. Similarity between the tasks causes resource allocation conflicts and leads to decreased performance (e.g., accuracy).

Complexity refers to the degree of difficulty of the interruption task. A complex interruption demands more cognitive resources and more severely impedes performance on the main task.

Timing refers to the stage of the primary task at which the interruption occurs. Research shows that an interruption in the middle of a process has a more deleterious effect on performance than one occurring in the beginning or at the end of a primary task (Corragio, 1990; Schuh, 1978).

Form of interruption refers to the media generating the interruption, such as e-mail messages, telephone calls or face-to-face interruption. Media that facilitate immediate feedback may cause severe interruptions because they are difficult to terminate.

Each message or package of information is associated with a source called its generator. The generator of an interruption (e.g., individual or machine) influences a performer's evaluation of the cost -benefit trade-off of responding or not responding to that interruption (e.g., interruption from one's boss vs. one's colleague).

The concept of social expectations has its roots in the organization culture literature and focuses on the influence of organizational culture on an individual's response to interruptions.
Same

Same

Content of interruption refers to the (perceived) relevance of an interruption message to the decision task at hand. It depends on both the message and the type of consumer goal. For example, at a bookstore site, a consumer who is looking for a gift may regard an ad for jewelry as relevant, whereas someone who is looking for a specific book will completely ignore it.

Similar to an organizational setting, complexity refers to the degree of difficulty of processing the interruption message - whether it takes more time and cognitive resources to understand the message and its relation to the current task.

Timing refers to the stage of a decision process at which the interruption occurs. Because a consumer information search is more exploratory at the beginning of a decision process (e.g., forming a consideration set) and becomes more specific (e.g., focusing on a choice from the consideration set) at a later stage, a consumer may react to the same interruption message differently depending on the stage of the decision.

The Internet provides applications that support various degree of interactivity, such as e-mail message, agents, and chat rooms. Interruptions that require immediate feedback may have a different impact than those do not require immediate feedback (e.g., e-mail messages). In addition, different formats of interruption (e.g., side window vs. replacement window) can be produced and may impose a different degree of obtrusiveness and, therefore, have different impacts.

The generator of an interruption refers to the source of an interruption. A consumer's attitude toward the source (e.g., a specific company vs. a nonprofit organization) may influence the response the interruption. In addition, the source of an interruption can be related to the concept of source credibility and, hence, influences the perception of and response to the interruption.

In Internet consumer decision processes, the social expectations may arise from the normal social groups that influence consumption behavior and also new social groups, both real and virtual, that may be specially formed due to experience on the Internet. fects of such interruptions on performance and choice satisfaction have not been fully investigated.

Interruptions can attract people's attention but, at the same time, may potentially impose attentional overload (Norman $\&$ Bobrow, 1975). Therefore, consumers' acceptance of interruption messages may depend on the strength (i.e., frequency, expectation) of the interruptions. Further, consumers' preferences for information change during different stages of their decision processes (Svenson, 1992, 1996) and depend on their purchasing goals (Lawson, 1997;
Peterman, 1997). Such preference changes may also influence consumers' reactions to interruption messages.

All informationis notequal. Consumers are selective in their voluntary exposure to information not only in the postdecision stage (Festinger, 1957; Lord, Ross, \& Lepper, 1979; Russo, Medvec, \& Meloy, 1996; Svenson, 1992, 1996) but also in the predecision stage (Janis \& Mann, 1977; Russo, Meloy, \& Medvec, 1998). Because interruptions are part of the information to which consumers may be exposed during their decision processes, we propose that the timing and content of interrup- 
tions will influenceconsumer acceptanceand usage of the interruption messages. Therefore, such interruptions will have different effects. Interruptions that convey relevant information, appearearly in the decision processes, or both may be more likely to be attended to and used in decision processes, whereas those that are irrelevant, are shown in the late decision processes, or both may be ignored and lead to frustration.

Consumer goals, control, and process knowledge may moderate the effects of interruption. Consumer goals guide the allocation of both attention and resources for information processing. Therefore, reactions to interruption messages may well depend on the goals of the decision tasks.

Consumer control is another important moderating factor. Ariely (1999) showed that the sense of control is an important part of consumer decision process satisfaction. When consumers have the choice of ignoring the interruptions, severe negative emotions will possibly be alleviated. Finally, consumers' reaction to interruptions may also depend on their knowledge of their decision tasks and the interruption information.

Interruptions influence task performance and satisfaction. In most of the empirical research on interruptions, performance has been measured by time spent on the main task and decision accuracy. In general, interruptions tend to delay the achievement of the primary tasks and decrease decision accuracy. However, interruptions may serve a wider scope of functions in consumer decision processes. They could impede a decision process as well as facilitate it. Interruptions can divert a decision maker's attention and stretch the decision processes out, making them last longer, but they can also provide decision makers with shortcuts that lead them to the final choice faster. Therefore, further investigation is needed to specify conditions or characteristics of interruptions that can shorten or prolong consumer decision processes. In terms of decision performance measurement, effort spent on information search is a typical indicator used in consumer decision making (Hogarth, 1987; Johnson \& Payne, 1985). Effort describes the degree to which consumers try to carry out their decision processes and arrive at a better decision. It is positively correlated with accuracy, although effort does not guarantee better choices (Johnson \& Payne, 1985). Time spent on the task is usually used as an indicator of effort. In our studies, we used time spent as the major dependent variable to measure decision performance because we used a shopping task as stimuli, and there was no accuracy attached to the task.

In consumer decision making, decision makers usually would not get decision feedback until they have actually consumed the product. Therefore, consumer satisfaction with their choices is used as one of the indicators of decision effectiveness. Significant attention has been devoted in the literature to consumer satisfaction with choice (Anderson, Fornell, \& Lehmann, 1994; Oliver, 1980). Recent work has shown that decision satisfaction involves satisfaction with the choice as well as with the process of choice itself (Fitzsimons, Greenleaf, \& Lehmann, 1997; Zhang, 1999). Consumers differenti- ate between satisfaction with a product and with a decision process and make attributions to different parties for each (Fitzsimonset al., 1997). We use the term decision satisfaction to refer to all aspects related to consumer decision making. It includes both choice satisfaction and decision process satisfaction. We propose that interruptions may have a different impact on consumers' experiences from that on choices.

In the next section, we report on our empirical investigations of the effects of various characteristics of interruption on consumer decision-making performance and effectiveness. Figure 1 provides an overview of our investigation. We conducted four studies to examine the influence of interruption frequency, timing, content, and consumer expectation, as well as the moderating effects of consumer goals, control, and individualdifferences on time spent on decision task and satisfaction. A summary of the hypotheses, principal arguments for each hypothesis, and the results obtained is shown in Table 2.

\section{METHODOLOGY}

\section{Context of Experiments: Online Environment}

The development of Internet technologies provides consumers with another avenue for shopping. Although interruptions may happen in traditional shopping environment, we propose that they may be more salient in the online environment. First of all, the online environment is more information saturated (Bakos, 1997). Consumers face more product options and can obtain more information about these options online. More importantly, because all marketing stimuli are concentrated on the screen, interruptions could be more attention catching and impose a more salientinfluence on consumerinformation processing and decision processes. Second, interactivity is an inherent characteristic of online environment (Steuer, 1992).

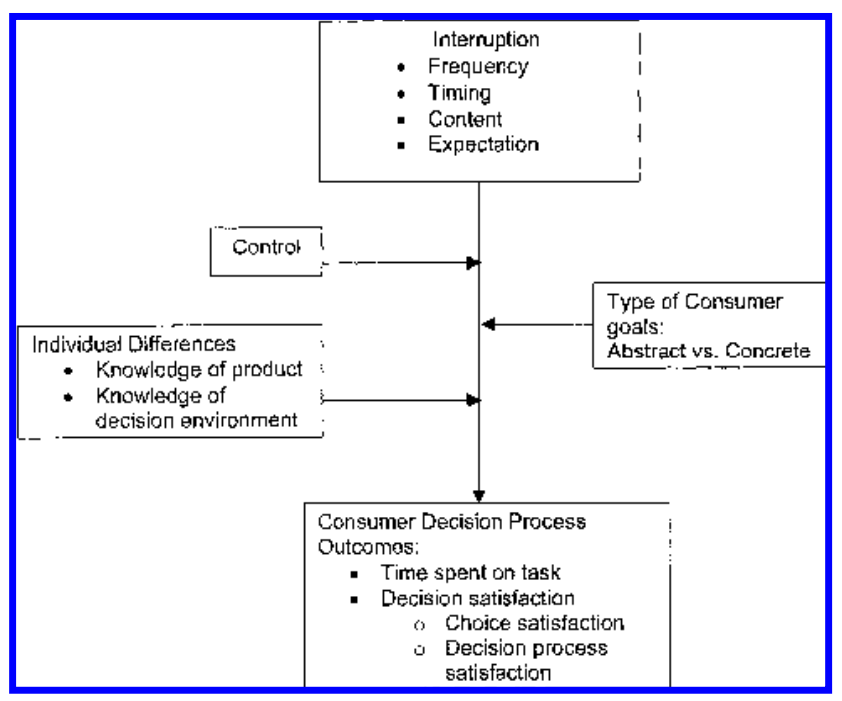

FIGURE 1 An investigation of interrupted decision processes. 
TABLE 2

Summary of Hypotheses and Results

\begin{tabular}{lc}
\hline Study & Hypothesis \\
\hline Study 1 & $\begin{array}{c}\text { H1: Interruptions will lead to more time being } \\
\text { spent on the task. }\end{array}$
\end{tabular}
spent on the task.

$\mathrm{H} 2$ : A moderate level of interruption frequency will increase the time spent on the task compared with a low or high level of interruption frequency.

H3: As interruption frequency increases, consumers with concrete goals will spend less time on the task, whereas those with abstract goals will not be affected.

H4: Interruptions will reduce consumers' decision process satisfaction but will not affect satisfaction with their choices.

H5: Interruptions will lead consumers with more knowledge about the products to spend more time on the task than those with less knowledge.

H6: When presented with interruptions, consumers with more experience (with the Internet) will spend less time on the task than those with less experience.

Study 2 H7: Consumers with control over interruptions will perceive the interruptions more positively than those without control.

H8: When given control, consumers will be less likely to process the interruption messages as the interruption frequency increases.

H9: When given control, consumers with abstract goals are more likely to process the interruptions than those with concrete goals.

Study 3 H10: Participants will show a more positive attitude toward early interruptions than late interruptions.

H11: Late interruptions lead to more time being spent on the task compared with that of early ones.

H12: Participants with abstract goals will spend more time when encountering late interruptions than early interruptions, whereas those with concrete goals will not be influenced by the timing of interruptions.

Study 4 H13: Participants will spend more time on the interruptions when they are relevant compared to when the interruptions are irrelevant.

H14: Irrelevant (relevant) information will increase (decrease) time spent on the task when participants expect to be interrupted and will decrease (increase) time spent when participants do not expect to be interrupted.
Major Arguments

Result

Interruptions are severe attentional distractions that place greater demands on cognitive processing resources than the available capacity can handle. They increase time to perform the primary task because extra time is necessary to backtrack and recover from the interruptions (Laird, Laird, \& Fruehling, 1983; Norman \& Bobrow, 1975).

A moderate level of interruption facilitates the main task, whereas a high level of interruption impedes performance on the main task (Yerkes \& Dodson, 1980).

Consumers with abstract goals differ from those with concrete goals in terms of their information needs (Lawson, 1997; Peterman, 1997). Those with abstract goals are open to a wider range of information than those with concrete goals.

There exist different dimensions of consumer satisfaction (Fitzsimons, Greenleaf, \& Lehmann, 1997). Consumers distinguish between satisfaction with choices from that with decision processes. Interruptions are potential experiences that may only influence decision processes.

Product expertise helps consumers to ignore irrelevant information (Alba \& Hutchinson, 1987; Hutchinson \& Alba, 1991). Consumer knowledge with the product (in the main task) can enhance the perceived relevance or interests in the task and, therefore, result in their persevering with the task despite the interruptions.

Decision makers with experience or knowledge of the decision environment will tend to be more efficient in handling its various processes, including interruptions, and reduce the time needed to backtrack.

When consumers have the choice of ignoring interruptions, they may feel less intruded on, and therefore, the potential negative effect of interruptions may be alleviated.

High interruption frequency increases attentional overload and leads to frustration (Laird et al., 1983; Norman \& Bobrow, 1975).

Consumers with abstract goals differ from those with concrete goals in terms of their information needs (Lawson, 1997; Peterman, 1997). Those with abstract goals are open to a wider range of information than those with concrete goals (same as H3).

Consumers tend to process information in an unbiased way and are more open to new information in the early stages of decision making (Svenson, 1992).

Because of preferences for information changes during different decision stages, early interruptions may be more easily processed and synthesized, whereas late interruptions may cause uncertainty of the tentative preferences formed (Svenson, 1992).

Participants with abstract goals will consider interruption messages as relevant and try to process and integrate such information. Information processing is more difficult for late interruptions when tentative preferences are already formed.

Consumers tend to selectively expose themselves to information that they consider as useful in their decision processes (Festinger, 1957; Lord, Ross, \& Lepper, 1979; Russo, Medvec, \& Malloy, 1996).

Moderate level of stimulation encourages performance more than a low or high level (Speier, 1996; Steenkamp \& Baumgartner, 1992). Irrelevant information and unexpected interruptions may form a high stimulation that frustrates participants compared with relevant information or expected interruptions.
Supported

Not supported

Supported

Supported

Supported

Supported

Supported

Supported

Supported

Not supported

Supported, but for other reasons

Supported, but for other reasons

Not supported

Inconclusive 
Although interactivity benefits consumers by providing timely and updated information, it can also take part of the control away from consumers, for example, by presenting information that consumers do not voluntarily seek. Using various technologies, the onlineenvironment can generate physiological interruption events using graphics and sounds and cognitive interruption events by presenting unexpected information. Finally, it is easier to simulate an online shopping environment while manipulating specific interruption characteristics and controlling other factors in a laboratory setting. Therefore, we chose online environment as our context of investigation. As we emphasized, the conceptualizationof interruptions applies to the traditional shopping environment, and empirical tests for other shopping contexts are also desirable.

\section{Stimuli}

A hypothetical electronic store was constructed with hypertext markup language. Snap shots of the stimuli are presented in Appendix A. Based on discussions with a small group representing the participant pool, the computer modem category was used as the main product category because it was expected and noticed that participants' knowledge about the product would be sufficiently varied and allow the effect of individual differences to be tested. Product information was selected from a real online store. A list of eight modems was presented in the main page. By following the links (products), participants could find a page that described the basic features of the product. Three more links were available at the bottom of each product description page, which led to more information about the product. The store interface was designed in such a way as to mimic real-world Web sites (i.e., information was organized through hyperlinks).

A computer program was written to generate interruptions ${ }^{3}$ and a log file that recorded participants' information search sequences and the time spent on each page. A "Ready to Decide" button on the interface allowed participants to end the information-acquisition process and proceed to answering a questionnaire that followed.

\section{Procedure and Measurement}

The experiments were conducted in a computer lab with IBM PCs in groups of 7 to 15 participants. The experimenter first explained the shopping task and demonstrated the interface of the program. Then, participants were instructed to navigate through the pages as they usually did on the Internet. On completion of the shopping task, they were asked to answer a

\footnotetext{
${ }^{3}$ The interruption messages were also selected from a real Web site. Interruptions presented information on different products still in the same product category (e.g., phones), which was considered relevant to those with abstract goals but irrelevant to those with concrete goals.
}

questionnaire. Participants' demographic information, experiences with the Internet, knowledge of the product, attitude, and perceived influence of the interruptions, ${ }^{4}$ satisfaction with decision processes and choice, and measures of manipulations were obtained. The computer program captured the major dependent variables used, namely, participants' time spent on the task, number of pages visited, time spent on interruptions, and interruption pages visited.

\section{HYPOTHESES AND EXPERIMENTS}

\section{Study 1: Interruption Frequency}

As previous empirical studies have suggested, interruptions distracted participants from this activity and demanded the allocation of cognitive capacity for processing the interruptions (Kahneman, 1973; Norman \& Bobrow, 1975). Interruptions led to extra time being needed for the original task (Speier, 1996). Therefore, we hypothesized that interruptions would influence decision processes by increasing the time spent on the task $(\mathrm{H}=$ hypothesis $)$ :

\section{H1: Interruptions will lead to more time being spent on the} task.

On the other hand, when there is interruption, the level of interruption should be appropriate so that the decision maker will still be motivated to proceed with the task (Yerkes \& Dodson, 1980). Beyond a threshold, interruptionsmay be seriously dysfunctional. As the frequency of interruption increases, cognitive demand may be very high, and the task may become onerous and cause severe frustration. Therefore, decision makers may be more likely to give up the task. Following the inverted-U-shape effects of interruptions on performance found in the existing literature, we hypothesized that

$\mathrm{H} 2$ : A moderate level of interruption frequency will increase the time spent on the task compared with a low or a high level of interruption frequency.

Next, we hypothesized the moderating effects of consumer goals. Lawson (1997) provided a goal-driven framework that combines alternative-driven and goal-driven modes for studying a wider range of consumer decision scenarios. Decision processes can start at any of four different levels of goals: value level, activity level, product-acquisition level, or brand-acquisition level. Concrete goals are directly linked to the generation of product-level consideration sets. Similarly, Peterman (1997) demonstrated that abstract goals have a differential effect on information acquisition and en-

\footnotetext{
${ }^{4}$ These items were tested in the pretest and refined for Studies 1 and 2. Items are displayed in Appendix B.
} 
coding from that of concrete goals. People with abstract goals tend to search across product categories and consider a wider range of information as relevant. Therefore, consumers with abstract goals differ from those with concrete goals in terms of their information needs. We proposed that the impact of interruptions is moderated by the type of goal driving a consumer's Internet activity and by individual differences across consumers. In the context of Internet shopping, buyers and shoppers may have different goals. Similarly, shopping for a computer and shopping for a gift may represent different goal specificity. When a consumer has an abstract goal, he or she may spend more time to explore the Internet for information and may consider a wider variety of product categories as relevant. On the other hand, when a consumer has a concrete goal, he or she may start with a more targeted search for information and treat other information as irrelevant. Therefore, interruptions may impose a more severe distraction and attentional overload to those with concrete goals than to those with abstract goals. We hypothesized that consumers with concrete goals would be more likely to be frustrated as interruption frequency increases, whereas those with abstract goals may not be as disturbed by interruptions:

H3: As interruption frequency increases, consumers with concrete goals will spend less time on the task, whereas those with abstract goals will not be affected.

Interruptions are potential experiences that consumers may have during their decision processes. We proposed that interruptions may influence a consumer's perception of whether the experience with the decision process was satisfactory but would not significantly influence their satisfaction with their choices:

H4: Interruptions will reduce a consumer's decision process satisfaction but will not affect satisfaction with their choices.

Finally, individual differences across consumers in terms of prior knowledge or familiarity with the products may moderate the effect of interruptions on decision performance and satisfaction. The literature has shown that consumers rely on their knowledge to guide information searching and processing (Alba \& Hutchinson, 1987). Also, product expertise helps consumers to ignore irrelevant information (Alba \& Hutchinson, 1987; Hutchinson \& Alba, 1991). In the context of Internet shopping, we proposed that both a consumer's knowledge of the product being considered and knowledge of the decision environment (i.e., Internet) would moderate the effects of interruptions. When encountering interruptions, consumer knowledge of the product being considered for purchase could enhance the perceived relevance or interests of the main task and, therefore, result in perseverance with the task despite the interruptions (H5). In addition, the Internet may be a new decision environment for some consumers, and they may differ in their ability to interact with it and navigate through it. Decision makers with experience or knowledge of the decision environment would tend to be more efficient in handling its various processes including interruptions and reduce time needed to backtrack; therefore, more experienced decision makers would spend less time on the task (H6):

H5: Interruptions will lead consumers with more knowledge about the products to spend more time on the task than those with less knowledge.

H6: When presented with interruptions, consumers with more experience (of the Internet) will spend less time on the task than those with less experience.

The hypotheses were tested with an Interruption Frequency (high, moderate, and low) $\times$ Consumer Goals (abstract vs. concrete) between-subject factorial design. A pretest was conducted to check the appropriateness of the stimuli and the manipulations.

Pretest. Forty-five undergraduate students from a large midwestern university participated in the experiment in return for extra credit for a class. In the pretest, frequency was manipulated by generating interruptions every minute (high frequency), every $2 \mathrm{~min}$ (moderate frequency), and every 3 min (low frequency). A control group (no interruption) was also used. We manipulated consumer goals by instructing participants to look for either a modem (concrete goal) or a communication device (abstract goal). This manipulation was adapted from Lawson's (1997) framework. The concrete goal was at brand-acquisition level, whereas the abstract goal was at product-acquisition level. The magnitude of the interruption (the time participants had to wait until they could resume their previous state) was set at $60 \mathrm{sec}$. Interruption messages were constructed with information about different products in the same product category (telephones and fax machines).

Two measures of interruption frequency were obtained. One was the actual number of interruptions that occurred, and the other was the participant's perception of interruption frequency. Both measures significantly correlated with the manipulated interruption frequency $(r \mathrm{~s}=.58$ and .89 , respectively). However, the distance between the low and moderate levels of interruption frequency was not significant. The goal manipulation was successful. Participants with concrete goals only perceived the modem as a relevant product, and those with abstract goals perceived a wider range of product categories (e.g., modems, phones) as relevant $(M \mathrm{~s}=3.5$ and 2.4 for the abstract goal and concrete goals, respectively, out of 5-point scales), $F(1,33)=13.6, p=.001$. Participants were fairly knowledgeable about phones $(M=4.1$ out of a 5 -point scale) and somewhat knowledgeable about modems ( $M=2.8$ out of a 5-point scale) and had limited knowledge about fax machines $(M=2.4$ out of a 5 -point scale). The 
amount of information $(M=2.7$ out of 5), information content $(M=3.4$ out of 5), and number of products provided $(M=3.2$ out of 5) were perceived as being just about at the middle of the scale.

The results suggest that participants did not have any difficulty in understanding the stimuli, and the information contained in the task was appropriate. The stimuli were adjusted based on the pretest. We adjusted interruption frequency to four levels (every 1, 2, 4, and $6.5 \mathrm{~min}$ ). In addition, we adjusted the magnitude of the interruptions to $30 \mathrm{sec}$ because it was observed that $60 \mathrm{sec}$ was so long that participants switched attention to other things after about $30 \mathrm{sec}$.

Study 1 overview. Study 1 employed forced interruptions. Participants could not turn the interruptions off and had to wait $30 \mathrm{sec}$. Most interruptions studied in existing literature have been based on forced interruptions. Therefore, it served as a baseline to show the effects of online interruptions, which are usually controlled by users. Ninety-five undergraduate students from a midwestern university participated in the study. Data from 89 students were usable after those with technical problems (e.g., incomplete data records) were discarded.

Manipulation check. The adjusted frequency manipulation was successful. A four-item scale was constructed to measure participants' perception of interruption frequency $(\alpha$ $=.83$ ). The four items converged to one factor (common factor) that accounted for $59.4 \%$ of the variance. Manipulatedinterruption frequency was significantly correlated with the actual number of interruptions that occurred $(r=.85)$ and participants' perception of interruption frequency $(r=.62)$. Results of a one-way analysis of variance (ANOVA) and multiple-comparison (Tukey) analysis showed that there was no significant difference between interruption frequencies of lengths 4 and $6.5 \mathrm{~min}$. So, we reconstructed a frequency index by combining 4- and 6.5-min interruptions. We formed a no-interruption group by grouping together those who did not encounter any interruptions. No significant difference in terms of amount of time spent on the task was found between the constructed no-interruption group with the control group in the pretest. Therefore, three levels of interruption, low frequency (4 or $6.5 \mathrm{~min}$ ), moderate frequency ( $2 \mathrm{~min}$ ), and high frequency (1 $\mathrm{min})$, and a constructed control group were used

TABLE 3

Manipulation of Interruption Frequency

\begin{tabular}{lcc}
\hline $\begin{array}{l}\text { Interruption } \\
\text { Frequency }\end{array}$ & Manipulation & $\begin{array}{c}\text { M Interruptions } \\
\text { Occurred }\end{array}$ \\
\hline High frequency & Every $1 \mathrm{~min}$ & 5.6 \\
Moderate frequency & Every 2 min & 2.8 \\
Low frequency & Every 4 or 6.5 min & 1.1 \\
No interruption & No interruption & 0.0 \\
\hline
\end{tabular}

for further analysis. Table 3 summarizes the manipulation of interruption frequency.

Results. When interruption groups were compared with the control group, results showed that interruptions increased the time spent on the task, $F(1,87)=17.28, p<.001$, and the number of pages visited, $F(1,87)=15.1, p<.001$. H1 was thus supported. However, H2 was not supported. Low interruption frequency was marginally different from high interruption frequency ( $p=.091)$ in terms of amount of time spent, but moderate frequency was not different from the other two. Instead of the inverted-U-shape relation hypothesized, there was a decreasing linear trend as interruptionfrequency increased. Table 4 showed the average time spent and number of pages visited for each level of interruption frequency.

A two-way ANOVA with goal and interruption frequency as independent variables showed a significant interaction effect, $F(2,77)=7.85, p<.001$ (see Figure 2). As interruption frequency increased, participants with concrete goals showed a decreasing trend in time spent on the task, $F(1,38)=21.58$, $p<.000$, whereas those with abstract goals showed no significant changes. Therefore, H3 was supported. With participants' knowledge about the products (modem) and their experiences with the Internet as covariates, the ANOVA

TABLE 4

Mean Time Spent on the Task and the Average Number of Pages Visited (Study 1)

\begin{tabular}{lccc}
\hline $\begin{array}{l}\text { Interruption } \\
\text { Frequency }\end{array}$ & $n$ & $\begin{array}{c}\text { Time Spent } \\
\text { on Task (sec) }\end{array}$ & $\begin{array}{c}\text { Number of } \\
\text { Pages Visited }\end{array}$ \\
\hline High frequency & 24 & 366.2 & 27.6 \\
Moderate frequency & 22 & 383.8 & 30.3 \\
Low frequency & 32 & 420.1 & 30.4 \\
No interruption & 11 & 271.6 & 16.5 \\
Total & 89 & 378.2 & 27.9 \\
\hline
\end{tabular}

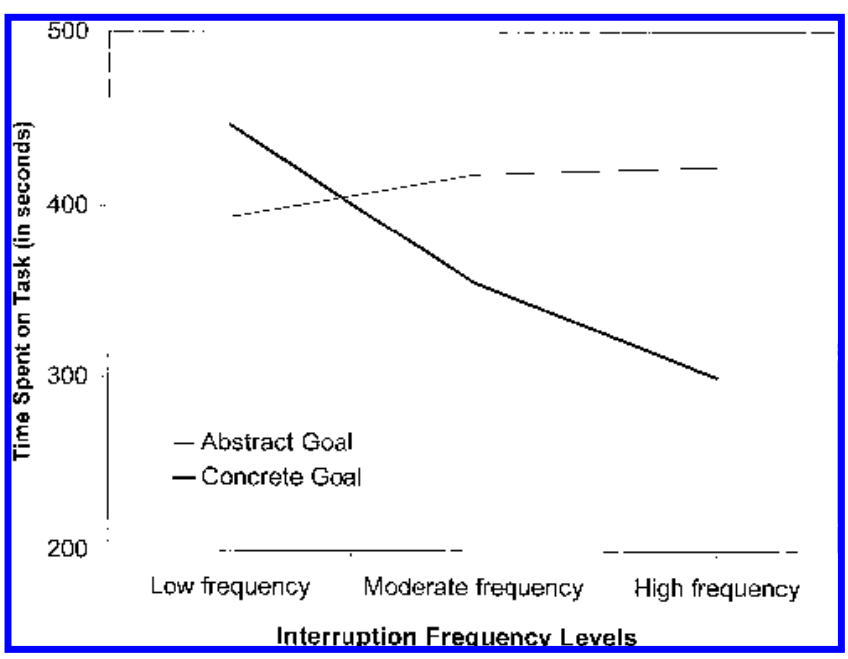

FIGURE 2 Time spent on task with different levels of interruption frequency. 
showed that higher levels of knowledge increased the time spent on the task, $F(1,76)=5.63, p=.02$, and more experiences with the Internet reduced the time spent on the task, $F(1,76)=4.7, p=.03$. Therefore, $\mathrm{H} 5$ and $\mathrm{H} 6$ were supported.

Participants' satisfaction with their choices and satisfaction with their shopping experiences were measured separately. There was no difference between the two types of satisfaction when there was no interruption $(M \mathrm{~s}=6$ and 5.2, respectively, out of 7-point scales). However, when there were interruptions, participants were significantlyless satisfied with their shopping experiences than with their choices $(M \mathrm{~s}=3.9$ and 5.6, respectively, out of 7-point scales), $t(61)=8.6, p<.000$. An ANOVA showed that interruptions significantly decreased satisfaction with the shopping experience, $F(1,86)=7.3, p=.008$, but not satisfaction with choice, $F(1,71)=2.2, p=.144$. H4 was supported. When different frequencies of interruption were compared, the high frequency of interruption significantly decreased decision processes satisfaction comparing with low and moderate levels of interruption, $F(2,75)=4, p=.023$, whereas there was no difference in satisfaction with choice. Consumer goals did not influence either type of satisfaction.

Discussion. Study 1 showed that interruptions increased the time participants spent on the task. Unfortunately, different levels of interruption frequency only showed marginally significant effects on amount of time spent. One reason could be that the frequency manipulations need to be further adjusted to capture substantial differences.

The study revealed the significant moderating effect of consumer goals. Participants with concrete goals spent less time on the task as interruption frequency increased, whereas those with abstract goals were not influenced. This result is consistent with our argument that people with abstract goals are open to a wider range of information and, therefore, can endure a higher interruption frequency than those with concrete goals. The interaction effect between goal and interruption showed that participants with concrete goals spent less time than those with abstract goals when interruption frequency was low, but the effect was reversed when interruption frequency was high. A possible explanation for this interaction effect may reside in the participants' perception of distance to achieving their goals. A concrete goal tends to have a shorter distance from goal attainment, whereas an abstract goal tends to have a longer distance because an abstract goal has to be settled on something concrete before any (purchase) decision can be made. Therefore, in this situation, participants with concrete goals may have been more likely than those with abstract goals to spend more time to attain their goals under low frequency of interruption but experienced higher frustration under high frequency of interruption and, therefore, were more likely to give up. On the other hand, participants with abstract goals were less influenced by the changes of interruption frequency because of their perceived relatively longer distance from achieving their goals.
Also consistent with out prediction, interruptions reduced participants' satisfaction with their shopping experiences (decision processes) without influencing their satisfaction with the choices. It provided further evidence that satisfaction with the product purchased can be distinguished from satisfaction with the processes that consumers make their choices. Because consumers may make different attributions based on the two different types of satisfaction (Fitzsimons et al., 1997), future research should investigate the influence of the discrepancy of two types of satisfaction on subsequent decision behaviors.

\section{Study 2: Effects of Consumer Control}

Bagozzi (1997) suggested that consumer control is an important factor that influences consumer decision making and consumption. We proposed that it moderates the effects of interruptions on performance. When consumers have the choice of ignoring the interruptions, they may feel less intruded on, and therefore, the potential negative effect of interruptions may be muted $(\mathrm{H} 7)$. In addition, when given control, the amount of attention that consumers would devote to the interruptions may be influenced by interruption frequency and consumer goals. Because a higher interruption frequency may lead to frustration and dissatisfaction with decision processes, decision makers are more likely to exercise their control by turning off the interruptions (H8). Again, we expected the moderating effect of consumer goals. Participants with abstract goals may be more attracted to interruption messages because they search for a relatively broader scope of information than do those with concrete goals (H9). Therefore, we hypothesized that

H7: Consumers with control over interruptions will perceive the interruptions more positively than those without control.

H8: When given control, consumers will be less likely to process the interruption messages as interruption frequency increases.

H9: When given control, consumers with abstract goals are more likely to process the interruptions than those with concrete goals.

H7 through H9 were tested in Study 2.

Study 2 overview. Study 2 used the same factors as in Study 1, but participants had the choice of closing the interruption window if they did not want to read the interruption messages. In addition, because there was no significant difference between the 4-and 6.5-min interruption intervals, the 6.5-min level was dropped. Sixty-five undergraduate students participated in the study, and 62 data points were used for final analysis. Manipulations were successful as in Study 1. In addition to the dependent variables of Study 1, data on 
how participants handled the interruptions were collected (because they had control over the interruptions). These included time spent on the interruptions and number of interruption pages visited.

Results. The results were similar in pattern to those of Study 1. Interruption influenced time spent on the task, $F(1$, $61)=8.47, p=.005$. The same interaction effect between goal and interruption frequency was also found, $F(2,58)=$ $5.62, p=.006$.

When control over the interruptions was given, the type of goal had a significant main effect on time spent on the task, $F(1,58)=5.5, p=.022$. Participants with abstract goals spent more time than those with concrete goals $(M \mathrm{~s}=404.4$ and $337.2 \mathrm{sec}$, respectively). Interestingly, although interruptions still led to less satisfaction with decision processes than with choices, giving participants control over the interruptions alleviated the negative impact of high interruption frequency. In other words, when participants had control, a high interruption frequency did not lead to significantly lower satisfaction with decision processes.

Descriptive statistics on participants' responses to interruptions are shown in Table 5. An analysis of participants' responses to interruptions showed that interruption frequency influenced the time spent on each interruption, $F(2$, $58)=6.6, p=.003$, and marginally influenced the number of interruption pages visited per interruption, $F(2,58)=$
$2.99, p=.058$. Participants spent less time looking at interruption messages and visited less interruption pages as interruption frequency increased. The linear trend was significant, $F(1,58)=5.8, p=.019$. So, $\mathrm{H} 8$ was supported. Further, the type of goal significantly influenced the number of interruption pages they visited, $F(1,58)=6.4, p=$ .014 , and the total time spent on interruptions, $F(1,58)=$ $3.97, p=.051$. Participants with abstract goals spent more time and visited more interruption pages $(M \mathrm{~s}=90.1 \mathrm{sec}$ and 6.9 pages) than those with concrete goals $(M \mathrm{~s}=53.4 \mathrm{sec}$ and 4.2 pages). Therefore, $\mathrm{H} 9$ was supported.

Further, time spent on the interruptions was broken down to the time spent on each interruption, and a trend analysis was conducted to examine the influence of interruption sequence. Results showed a significant linear trend for participants with concrete goals under high and moderate interruption (see Figure 3). For participants with abstract goals, the trend disappeared under high interruption frequency, but there was no linear trend under moderate interruption frequency. Under low interruption frequency, there was no difference between participants with different types of goal. The trend analysis provided support that people with abstract goals can bear more interruptions than those with concrete goals to a certain level.

We pooled the data of Study 2 with those of Study 1 to further examine the effects of control. A factor analysis (common factor) was performed on the multiple items measuring consumer attitude and the perceived influence of interrup-

TABLE 5

Descriptive Statistics on Response to Interruption (Study 2)

\begin{tabular}{lcccc}
\hline $\begin{array}{l}\text { Interruption } \\
\text { Frequency }\end{array}$ & $n$ & $\begin{array}{c}\text { Total Time Spent on } \\
\text { Interruptions (sec) }\end{array}$ & $\begin{array}{c}\text { Total Number of Interruption } \\
\text { Pages Visited }\end{array}$ & $\begin{array}{c}\text { Time Spent per } \\
\text { Interruption }\end{array}$ \\
\hline High frequency & 24 & 94.8 & 8.7 & 13 \\
Moderate frequency & 19 & 68.1 & 4.3 & 16.6 \\
Low frequency & 16 & 40.4 & 2.8 & 26.8 \\
Total & 59 & 71.4 & 5.7 & 1.2 \\
\hline
\end{tabular}

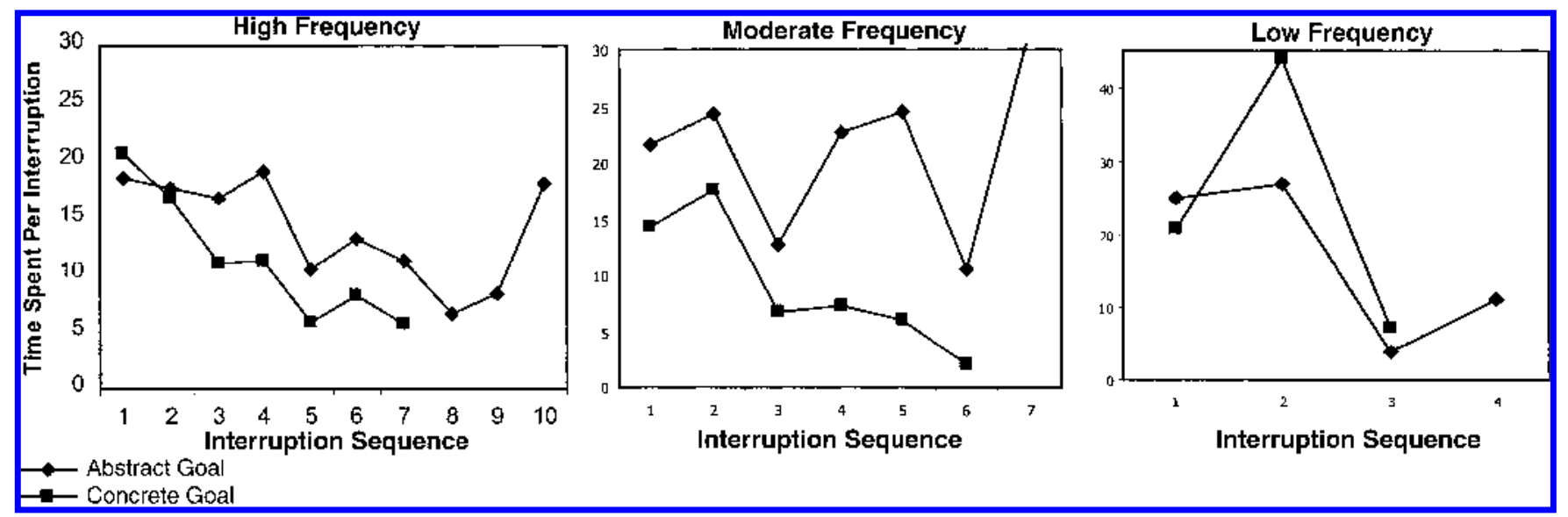


tions. Two factors explaining $51.3 \%$ of the variances were obtained and were interpretable. A two-way ANOVA with control and interruption frequency as factors showed that when participants had control, they liked the interruptions better, $F(1,128)=5.4, p=.021$. So, $\mathrm{H} 7$ was supported. There was also a main effect of interruption frequency. As interruptions became more frequent, the preference for interruptions decreased. However, participants felt that interruptions made their decision processes more difficult than those without control, $F(1,128)=4.7, p=.033$. This could be because, given control over the interruptions, participants had even more decisions to make (e.g., whether to look at the interruptions and how much time to spend on them). As interruption frequency increased, the perceived difficulty in making a decision increased, $F(1,128)=7.8, p=.001$. Control had no significant influence on time spent on the task or satisfaction.

Discussion. Study 2 revealed a similar pattern of the effects of interruptions on time spent on task, which enhanced the robustness of Study 1. Interruptions increased time spent on the task, and interruption frequencies interacted with types of goal. The main purpose of Study 2 was to examine the effect of control over the interruptions. Results showed that when given control, participants had less negative attitudes toward the interruptions. Therefore, control alleviated, to some extent, participants' dissatisfaction with their decision processes. At the same time, this increased satisfaction with the decision processes did not lead to a sacrifice of time spent on the task. Participants with control spent as much time as those without control.

Participants' goals significantly influenced how they reacted to the interruptions. As predicted, when participants searched for information with an abstract goal in mind, they had wider latitudes of information acceptance. Therefore, they were more likely to process interruption messages and spend more time on it compared to those with concrete goals. However, even those with abstract goals became less likely to process the interruption messages as interruption frequency increased.

Interestingly, when given control, participants perceived that interruptions made their decision processes more difficult. It is counterintuitive at first thought because having control should make choices easier. A possible explanation is that when given control, participants had to decide whether to look at interruption messages, how much information they wanted, and how long they wanted to spend looking for it. As a result, they had more decisions to make. This may have led them to perceive the decision as being more difficult. Future research should examine the influence of the number of subdecisions and types of subdecisions on decision performance and satisfaction.

\section{Study 3: Timing of Interruptions}

Timing of interruption refers to the time (e.g., in the early or later decision stages) that interruptions occur. The literature has shown that consumer information needs vary according to different decision stages and consumers are very selective in voluntary exposure to information (Festinger, 1957; Lord et al., 1979; Russo et al., 1996). As we discussed in the earlier sections, consumers tend to process information in an unbiased way and are more open to new information in the early stages of decision making. As they form their tentative preferences, they tend to be more selective in accepting new information and even distort information to facilitate choices, reduce anticipated cognitive dissonance, or both. Therefore, early interruptions may be more easily processed and synthesized, whereas late interruptions may cause uncertainty toward the tentative preferences formed. Interruptions occurring in the late stage of decision processes may lead to more time being spent on the task. Therefore we hypothesized that

H10: Participants will show a more positive attitude toward early interruptions than toward late interruptions.

H11: Late interruptions will lead to more time being spent on the task compared with that for early interruptions

People with different goals may perceive the interruptions differently, and so the influence of interruptions may vary based on goals. Those with abstract goals are more likely to perceive interruptions as relevant and try to process and integrate such information. Information processing is more difficult for late interruptions when tentative preferences are formed. Therefore, the timing of interruption will influence their time spend on the decision task. However, the timing of interruptions may not be crucial when the interruptions are not relevant to the decision task at hand (to those with concrete goals):

H12: Participants with abstract goals will spend more time when encountering late interruptions than early interruptions, whereas those with concrete goals will not be influenced by the timing of interruptions.

Study 3 was conducted to test the previous hypotheses.

Study 3 overview. The purpose of Study 3 was to examine the influence of the timing of interruption on decision performances. It was a Timing (early vs. late) $\times$ Goal (abstract vs. concrete) factorial design. Timing was manipulated as two levels: early or late with respect to a participant's decision process. In the early condition, participants encountered two interruptions $40 \mathrm{sec}$ after they started the task. In the late condition, participants encountered interruptions twice when they formed their preferences and clicked the "Ready to Decide" button but before they stated their choices. Two other product categories (digital camera and audio systems) were added to the hypothetical store to make it more realistic. Goal was manipulated as concrete ("look for a modem") or abstract ("look for some electronics"). The content of the interrup- 
tions was relevant to participants with abstract goals but not to those with concrete goals. Forty-four students participated in the experiment. Forty data points were used for analysis.

Results. A two-way ANOVA showed a significant main effect for timing, $F(1,39)=4.86, p=.034$, and a significant interaction of timing and goal, $F(1,39)=6.93, p=.012$, (see Figure 4). Participants encountering late interruptions spent more time than those encountering early interruptions $(M \mathrm{~s}=355.3$ and $290.9 \mathrm{sec}$, respectively). Participants with abstract goals spent more time than those with concrete goals when interruptions occurred in the late stage of their decision processes ( 375.5 vs. $335 \mathrm{sec}$ ), but the reverse was true when interruptions occurred in early stage of decision processes (234.5 vs. 347.4). So, H11 and H12 were supported. The number of pages visited also showed such an interaction effect, $F(1,39)=4.86, p=.03$. Similar to Study 2, participants with abstract goals spent more time on interruptions than those with concrete goals $(M \mathrm{~s}=19.9$ and $8.6 \mathrm{sec}$, respectively), $F(1,39)=11.02, p=.02$. They were also more satisfied with their choices than those with concrete goals, $F(1$, $25)=6.39, p=.018$.

H11 and H12 were, however, supported for reasons other than those discussed in their development.Participantsdid not perceive early interruptions as useful and easily integrated into their decision processes compared to late interruptions. On the contrary, early interruptions were perceived as making decision processes more difficult, $F(1,23)=4.97, p=.037$. Similarly, participants perceived being more interrupted when they encountered early interruptions than when they encountered late interruptions, $F(1,19)=5.57, p=.03$. Therefore, it could be inferred that early interruptions frustrated participants with abstract goals as they were trying to integrate the new information into their cognitions, and as a result, they spent less time on the task. While under the condition of late interruptions, participants already had a tentative choice and could easily ignore the interruptions or process them without any further integration into the decision processes.

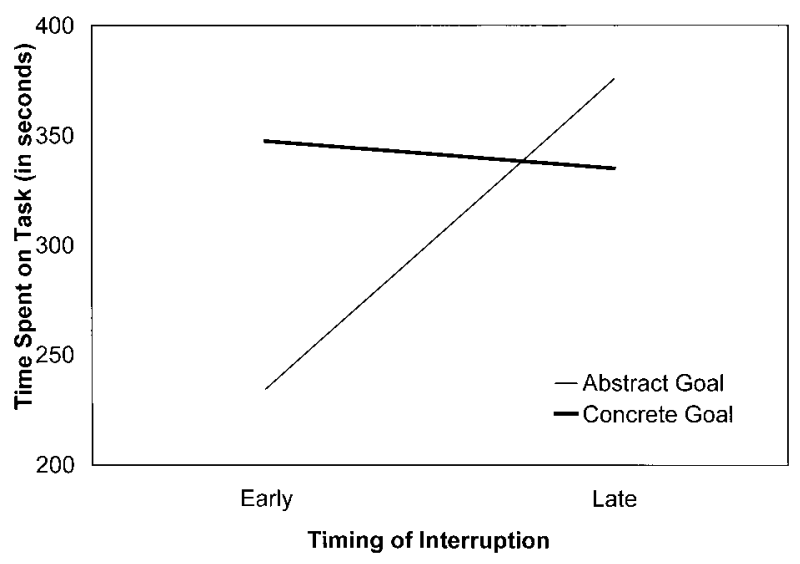

FIGURE 4 Influence of timing of interruption on time spent on task.
Timing did not influence participants' attitude toward the interruptions; therefore, H10 was not supported. However, data showed that participants with abstract goals liked the interruptions better than those with concrete goals, $F(1,32)=$ $10.31, p=.003$.

Discussion. Study 3 provided some surprising results. Although participants' viewing time showed the hypothesized pattern, it revealed different reasons for the observed effects. Interruptions may not be a good format to present information that is related to the decision task because of the perceived burden in decision difficulty. Presented early, participants may have difficulty in integrating the information into the decision processes; therefore, they get frustrated and end the decision task quickly. Presented late, it would not influence decisions at all. There is some indirect evidence for this explanation. For example, participants perceived VCRs as relevant to their shopping goal, but when information about VCRs was presented as interruptions, they perceived it as irrelevant. Therefore, it may be better to present such information in the traditional fashion rather than as interruptions. On the other hand, late interruptions could be potentiallyused to present new information that is unrelated to the decision task to switch participants' attentioninstead of trying to influence decision in the last minute.

The timing of interruptions did not at all influence the viewing patterns of participants with concrete goals. It did not influence either their time spent on the decision task or the time spent on the interruption messages. Examining consumers' perceptions of interruptions showed that when interruptions were presented at a late stage, they were not even perceived as being interruptions. Presumably, interruptions at that stage were not seen as being related to their decision task, and so there was no difficulty imposed on the task.

Study 3 suggested that content of interruptions may be an important factor that influenced the effects. In Study 4, we examined the impact of interruption content and the participants' expectation of interruptions.

\section{Study 4: Interruption Content and Expectations}

Consumers tend to selectively expose themselves to information that they consider as useful in their decision processes (Festinger, 1957; Lord et al., 1979; Russo et al., 1996). Therefore, relevant information may be more likely to attract participants' attention compared with irrelevant information (H13).

Further, content and expectation may work as factors that increase a participant's stimulation level. Both research in interruptions and consumer behavior suggest that a moderate level of stimulation encourages performance more than a low or high level (Donovan, Rossiter, Marcoolyn, \& Nesdale, 
1994; Speier, 1996; Steenkamp \& Baumgartner, 1992). In terms of interruptions, irrelevant information and unexpected interruptions may form a high stimulation that frustrates participants compared with relevant or expected interruptions. Therefore, when participants expect interruptions, irrelevant information imposes a moderate level of stimulation, and participants will spend more time on the task compared with relevant information. On the other hand, when participants do not have expectations of interruptions, irrelevant information will increase the already high level of stimulation, therefore leading to shorter times spent on the task compared when relevant information is presented (H13, H14). To summarize, the hypotheses were

H13: Participants will spend more time on the interruptions when they are relevant compared to when the interruptions are irrelevant.

H14: Irrelevant (relevant) information will increase (decrease) time spent on the task when participants expect to be interrupted and decrease (increase) time spent when participants do not expect to be interrupted.

Study 4 overview. Study 4 was an Interruption Content (relevant vs. irrelevant interruption) $\times$ Expectation (with vs. without expectation) factorial design. Expectation was manipulated by warning participants beforehand that they might encounter extra information during their task. We manipulated interruption content by providing either facilitating information (i.e., product information that within the scope of participants' task) or unrelated information (i.e., information on store reconstruction or statistics on e-commerce). An abstract goal ("buy some electronics") was provided. Thirty-six student participants participated in the experiment. Thirty-three data points were left for analysis.

Results. A two-way ANOVA showed no significant main effect of either factor on total time spent on the task or on the interruption messages. H13 was not supported. However, there was a significant interaction between expectation and interruption content, $F(1,32)=5.02, p=.033$ (see Figure 5). When participants expected interruptions, they spent more time when interruptions were irrelevant than when interruptions were relevant. When participants had no expectation of interruptions, the effect was reversed. The number of pages visited showed the same pattern, $F(1,32)=8.67, p=.006$. Therefore, the pattern hypothesized by $\mathrm{H} 14$ was supported. However, the measure of participants' arousal did not provide support for the hypothesized reason behind the pattern. No significant difference in arousal level among conditions was found. Therefore, $\mathrm{H} 14$ was inconclusive.

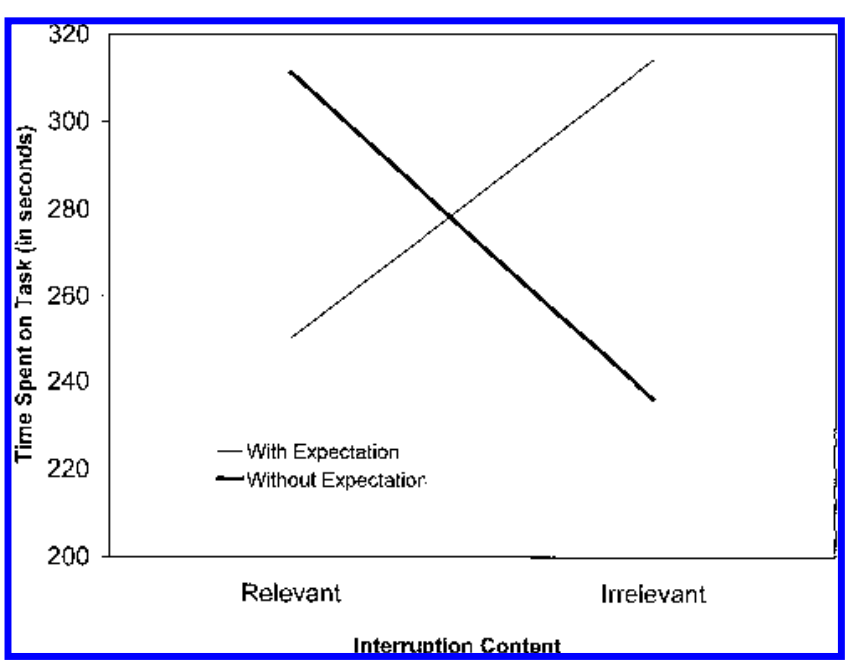

FIGURE 5 Influence of interruption content and expectation on time spent on task.

Discussion. Study 4 showed that information content did not influence either time spent on the task or time spent on interruptions. One possible reason could be the weak manipulation of relevance. Because participants were given an abstract goal to start with, the perceived relevance of the interruption messages provided might have been weaker compared with when the interruptions met their specific goals. Further, the small sample size may have attributed to the lack of main effect. Therefore, Study 4 needs future replication.

Although the results showed the expected interaction effect, the proposed underlying mechanism of the interaction was not supported. An alternative explanation for the interaction could be the preimposed effect of expectations. When participants were prepared for interruptions, they might have expected useful information and kept themselves open to potential information. Therefore, relevant interruptions would have been counted as information used in decision processes, and it reduced time spent on the task, whereas irrelevant information did not count, but it took time for participants to recover from the interference caused by such interruptions. However, when they were not prepared for interruptions, they might not have been as open and ready for outside interference. So when they encountered facilitating interruptions, they might have spent some time trying to assimilate it, but when interruptions were not relevant, they might have gotten frustrated and given up by shortening the time spent on the task. Our data provided some indirect support for this argument. When participants expected to be interrupted, they indicated that they would like to see more similar interruptions when interruptions were relevant than when they were irrelevant, but they did not want to see either when not expecting any interruptions.

Together with Study 3, it is suggested that interruptions can be used to present information that people can use in their decision tasks or as a device to switch their attention to some- 
thing else and obtain longer viewing time per visiting session. Information that is relevant to this task could function better if presented early in the decision task with some degree of surprise. On the other hand, irrelevant information that is used to switch a viewer's attention would function better if presented at the end of a decision task with warning beforehand.

\section{GENERAL DISCUSSION}

We studied the effects of four characteristics of interruption on decision process. Our studies showed that interruptionsincreased the time spent on the task and the amount of information searched for. High interruption frequency decreased time spent, possibly because of the higher frustration that participants experienced.

Results showed that consumer goals moderated the influence of interruption frequency on task performance. At a low level of interruption, participants with concrete goals spent more time on the task than those with abstract goals. At high or moderate levels of interruptions, the effects were reversed. As we discussed, this could be the effect of the perceived distance from goal achievement. In addition, participants with different goals might have behaved differently in terms of the direction of information search and latitude of information acceptance (Svenson, 1992). Our data were consistent with such a tendency. For example, when given control, participants with abstract goals were more likely to examine the interruption messages and spend more time on it. In addition, participants with concrete goals may have been more likely to get frustrated; therefore, interruption frequency had a more drastic influence on their decision performance.

Control over interruptions led to better attitudes toward the interruptions. Therefore, giving consumers control over interruption messages should have had a positive effect. However, data showed that when they had control, participants perceived an increased level of decision difficulty. Therefore, control and level of control should be balanced to gain the best effects.

Timing is anotherimportant factor in influencing the effects of interruptions. Early interruptions were more likely to increase decision difficulty, especially when the interruption messages were relevant. Such perceived decision difficulty may have increased the level of frustration and led to shortened decision processes. On the other hand, late interruptionstended to be perceived as less relevant; therefore, they did not add to decision difficulty. Participants with abstract goals actually spent more time on the task as well as on the interruption messages when interruptions occurred at a later stage. The effect of timing suggests that providing unexpected information at the end of a shopping task can catch consumers' attention and divert it to something else that the shopper may be interested in, therefore, prolonging the viewing time. This is consistent with Adar and Huberman's (1999) suggestion that providing coupons or information (of other products) at the end of a shopping task can benefit marketers by increasing browsing time.
Content of information did not exert significant influence on the effects of interruption. Although participants with abstract goals perceived the information as relevant, the added decision difficulty overweighed the usefulness of the information provided. Therefore, the implication is that useful information may be better presented in the traditional way, whereas interruptions are better used as a way to divert a consumer's interests after finishing this shopping task.

\section{LIMITATIONS AND FUTURE RESEARCH}

The research reported in this article, like most research, has its limitations. First of all, the main dependent measure of the studies was time spent on decision task. This measure is commonly used as one of the indicators of consumer thought processes during decision making; it does not, in and of itself, provide insights on how information is processed during that time. We would need to measure concurrent verbal protocols for a replicate group to more deeply understand the effects of interruptions on information-processingmechanisms. In such studies, we expect that interruption messages would have a greater effect on consumers who have less specific goals and have a wider scope of information acceptance than on others. For such consumers and perhaps others, we expect that the influence of interruptions on consumer information encoding and memory would vary depending on the characteristics of the interruption.

Second, time spent is only one of the indicators of task performance. It does not provide a full picture on the influence of interruptions on decision task performance by itself. In future research, the shopping task can be modified to obtain accuracy measures.

Third, because the dependent measure was time spent on task, the underlining mechanism of some hypotheses could not be unambiguously interpreted. The post hoc explanations and other possible interpretations of the results should be verified in future studies. For example, the role of interruptionexpectationneeds to be furtherinvestigated.Study 4 showed that expectation should be used carefully in conjunction with content or other factors to be potentially effective. Finally, this research investigated only a few characteristics of interruptions and their effects. Other interruption characteristics and their potential interactions should be further studied.

\section{IMPLICATIONS}

As more potential consumers gain access to the Internet, it is becoming a very important decision context in which to study consumer decision making. Although the Internet reduces consumer information search costs (Bakos, 1997), it is not realistic to assume that all consumers will exhaustively search for information and purchase the unconstrained optimal product. As the literature has shown, consumers are more likely to be cognitive misers than decision optimizers (Hogarth, 1987). Even on the Internet, consumer attention continues to remain the scarce resource for which marketers compete. For many Internet com- 
panies and Web sites, interruptions are a key part of the business model. However, marketers should be very cautious in using this mechanism. First, the influence of interruptions depends on information-processing goals. Therefore, to use the interruption mechanism effectively, marketers should pay attention to goal type of a Web site visitor. Second, interruptions may cause negative feelings. Our results showed that interruptions (especially frequent interruptions) decreased satisfaction with shopping experiences, although it did not influence satisfaction with choice. It is likely that consumers may attribute their negative feelings with a decision process to the medium, that is, the Web site instead of the product itself (Fitzsimons et al., 1997). From our results, it also appears that there might be an optimal frequency of interruption. Some interruptions may indeed be helpful, especially when the goal being pursued is an abstract one.

Our results suggested that giving control over interruptions to consumers could enhance the attractiveness of interruptions without sacrificing viewing time. When given control, people had a more positive attitude toward interruptions, and this enhanced their satisfaction with the decision processes. In addition, timing and consumer expectation should be strategically used together with the content and purposes of interruptions to achieve better results. For example, presenting information other than that which consumers could use in their current decision task at the end of the decision process and providing alerts of such interruptions beforehand could be a good strategy to attract and switch consumers' attention and to retain consumers at the Web site.

With more consumers being attracted to the Internet and marketers utilizing advanced technologies, communications between consumers and marketers are becoming more interactive. Marketers can now provide intelligent agents to make suggestions to consumers, use interactive banner ads to attract their attention, and provide different types of interactive cues to guide consumer navigation on the Internet. These may impose interruptions on consumers from a cognitive perspective. These interruptionscould be effective tools to deliver the right information to the right consumers at the right time. However, used inappropriately, they may overload consumer cognitive capacity and lead to frustration and negative affect. Therefore, future research is needed to fully understand the effectiveness of interruptions.

\section{ACKNOWLEDGMENTS}

We thank Madhubalan Viswanathan, the editor Dawn Iacobucci, and several reviewers for their comments on earlier drafts of this article. We thank Hong $\mathrm{Gu}$ for his technical support in data collection. We also thank Intel for an equipment grant to D. Sudharshan.

\section{REFERENCES}

Adar, Eytan, \& Huberman, Bernardo A. (1999). The economics of surfing. Quarterly Journal of Electronic Commerce, 1, 203-214.
Alba, Joseph W., \& Hutchinson, J. Wesley. (1987). Dimensions of consumer expertise. Journal of Consumer Research, 13, 411-454.

Alba, Joseph, Lynch, John, Weitz, Barton, Janiszewski, Chris, Lutz, Richard, Sawyer, Alan, \& Wood, Stacy. (1997). Interactive home shopping: Consumer, retailer, and manufacturer incentives to participate in electronic marketplaces. Journal of Marketing, 61, 38-53.

Anderson, Eugene W., Fornell, Claes, \& Lehmann, Donald R. (1994). Customer satisfaction, market share, and profitability. Journal of Marketing, 58, 53-66.

Ariely, Dan. (1999). Controlling the information flow: The role of interactivity in consumers' decision making and preferences (Working paper). Cambridge: Massachusetts Institute of Technology.

Bagozzi, Richard P. (1997). Goal-directed behaviors in marketing: The role of emotion, volition and motivation. Psychology \& Marketing, 14, 309-313.

Bakos, J. Yannis. (1997). Reducing buyer search costs: Implications for electronic marketplaces. Management Science, 43, 1676-1692.

Baron, Robert S., Baron, Penny H., \& Miller, Norman. (1973). The relation between distraction and persuasion. Psychological Bulletin, 80, 310-323.

Bettman, James R. (1979). An information processing theory of consumer choice. Reading, MA: Addison-Wesley.

Bettman, James R. (1988). Presidential address: Processes of adaptivity in decision making. Advances in Consumer Research, 15, 1-4.

Bettman, James R., Johnson, Eric J., Luce, Mary Frances, \& Payne, John W. (1993). Correlation, conflict, and choice. Journal of Experimental Psychology: Learning, Memory, and Cognition, 19, 931-951.

- Bettman, James R., \& Kakkar, Pradeen. (1977). Effects of information presentation format on consumer information acquisition strategies. Journal of Consumer Research, 3, 233-240.

- Bettman, James R., Luce, Mary Frances, \& Payne, John W. (1998). Constructive consumer choice processes. Journal of Consumer Research, 25(3), 187-217.

Corragio, Louis. (1990). Deleterious effects of intermittent interruptionson the task performance of knowledge workers: A laboratoryinvestigation. Unpublished doctoral dissertation, University of Arizona, Tucson.

Coupey, Eloise. (1994). Restructuring: Constructive processing of information displays in consumer choice. Journal of Consumer Research, 21, 83-99.

Donovan, Robert J., Rossiter, John R., Marcoolyn, Gilian, \& Nesdale, Andrew. (1994). Store atmosphere and purchasing behavior. Journal of

Festinger, Leon. (1957). A theory of cognitive dissonance. Stanford, CA: Stanford University Press.

Fitzsimons, Gavan J., Greenleaf, Eric A., \& Lehmann, Donald R. (1997). Decision and consumption satisfaction: Implicationsfor channel relations (Working Paper No. 313). Los Angeles: University of California, Los Angeles, John E. Anderson Graduate School of Management, Marketing Studies Center.

Hogarth, Robin. (1987). Judgment and choice: The psychology of decisions (2nd ed.). Chichester, England: Wiley.

Howard, John A., \& Sheth, Jagdish N. (1969). The theory of buyer behavior. New York: Wiley.

- Hutchinson, J. Wesley, \& Alba, Joseph W. (1991). Ignoring irrelevant information: Situational determinants of consumer learning. Journal of Consumer Research, 18, 325-345.

Janis, Irving Lester, \& Mann, Leon. (1977). Decision making : A psychological analysis of conflict, choice, and commitment. New York: Free Press.

Johnson, Eric J., \& Payne, John W. (1985). Effort and accuracy in choice. Management Science, 31, 359-414.

Kahneman, Daniel. (1973). Attention and effort. Englewood Cliffs, NJ: Prentice Hall.

Laird, D. A., Laird, E. C., \& Fruehling, R. T. (1983). Psychology and human relations and work adjustment. New York: McGraw-Hill.

Lawson, Robert. (1997). Consumer decision making within a goal-driven framework. Psychology \& Marketing, 14, 427-449. 
Lord, Charles G., Ross, Lee, \& Lepper, Mark R. (1979). Biased assimilation and attitude polarization: The effects of prior theories on subsequently considered evidence. Journal of Personality and Social Psychology, 37, 2098-2109.

Mandel, Naomi, \& Johnson, Eric. (1999). Constructing preferences online: Can Web pages change what you want? (Working paper). Philadelphia: University of Pennsylvania, Wharton School.

Norman, Donald A., \& Bobrow, Daniel G. (1975). On data-limited and resource-limited processes. Cognitive Psychology, 7, 44-64.

Oliver, Richard L. (1980). A cognitive model of the antecedents and consequences of satisfaction decisions. Journal of Marketing Research, 17(4), 460-469.

Payne, John. W. (1982). Contingent decision behavior. Psychological Bulletin, 92, 382-402.

Peterman, Michelle L. (1997). The effects of concrete and abstract consumer goals on information processing. Psychology \& Marketing, 14, 561-584.

Russo, Edward J., Medvec, Victoria H., \& Meloy, Margaret G. (1996). The distortion of information during decisions. Organizational Behavior and Human Decision Processes, 66, 102-110.

Russo, Edward J., Meloy, Margaret G., \& Medvec, Victoria H. (1998). Predecisional distortion of product information. Journal of Marketing Research, 35, 438-452.

Speier, Cheri. (1996). The effect of task interruption and information presentation on individual decision making. Unpublished doctoral dissertation, Indiana University, Bloomington.

-Steenkamp, Jan-Benedict E., \& Baumgartner, Hans. (1992). The role of optimum stimulation level in exploratory consumer behavior. Journal of Consumer Research, 19, 434-448.

Steuer, Jonathan S. (1992). Defining virtual reality: Dimensions determining telepresence. Journal of Communication, 42(4), 73-93.

Svenson, Ola. (1992). Differentiation and consolidation theory of human decision making: A frame of reference for study of pre and post decision processes. Acta Psychologica, 80, 143-168.

-Svenson, Ola. (1996). Decision making and the search for fundamental psychological regularities: What can be learned from a process perspective. Organizational Behavior and Human Decision Process, 65, 252-267.

Yerkes, Robert M., \& Dodson, Janet D. (1980). The relation of strength of stimulus to rapidity of habit-formation. Journal of Comparative Neurology of Psychology, 18, 458-482.

Zhang, Shi. (1999). Choice-process satisfaction: The influence of attribute alignablity and option limitation. Organizational Behavior and Human Decision Performance, 77, 192-214.

\section{APPENDIX A: SNAP SHOTS OF EXPERIMENT STIMULI}

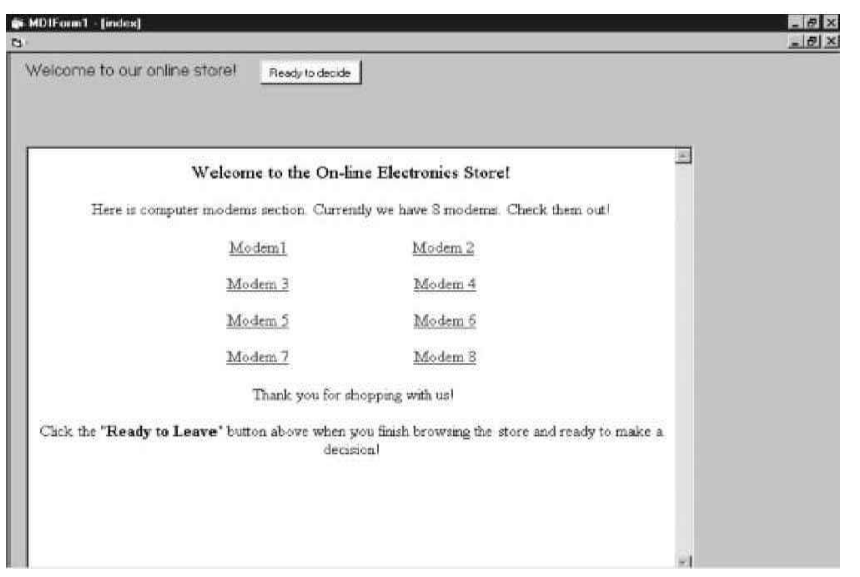

FIGURE A1 Main interface

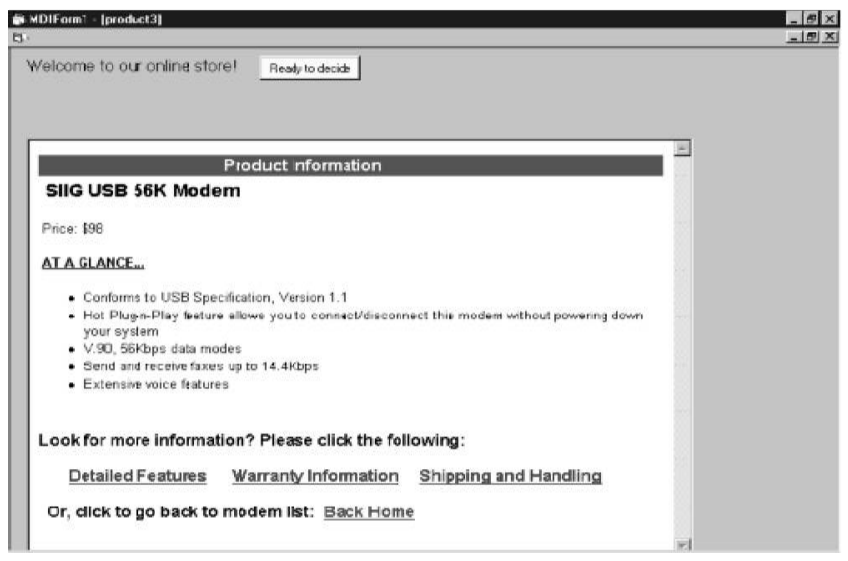

FIGURE A2 Example of a product information page

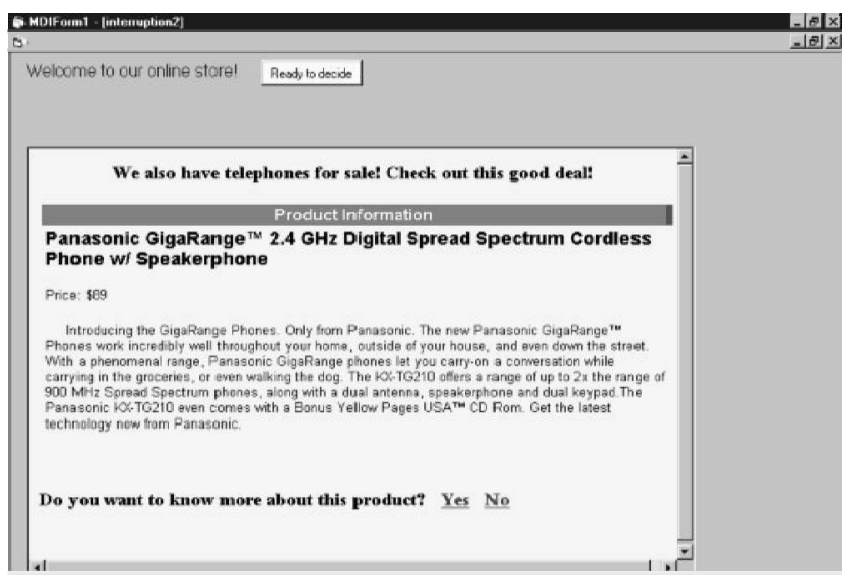

FIGURE A3 Example of an interruption page (with control in Study 2)

\section{APPENDIX B}

Measurement of Attitude Toward Interruption and Influence on Decision Performance

\begin{tabular}{|c|c|}
\hline Item & Description \\
\hline 1 & $\begin{array}{l}\text { The "pop-up information" made it difficult for me to decide } \\
\text { whether to buy a modem or a different product. }\end{array}$ \\
\hline 2 & $\begin{array}{l}\text { The "pop-up information" made it difficult for me to decide } \\
\text { which modem to buy. }\end{array}$ \\
\hline 3 & $\begin{array}{l}\text { The "pop-up information" helped me to make a better deci- } \\
\text { sion. }\end{array}$ \\
\hline 4 & I was curious about the "pop-up" information. \\
\hline 5 & $\begin{array}{l}\text { The "pop-up information" made my decision process diffi- } \\
\text { cult. }\end{array}$ \\
\hline 6 & I would like to have seen more such "pop-up information." \\
\hline 7 & $\begin{array}{l}\text { I would have spent more time to examine the modems } \\
\text { without the "pop-up information." }\end{array}$ \\
\hline 8 & I did not pay much attention to the "pop-up information." \\
\hline 9 & I would be more happy without the pop-up information." \\
\hline 10 & The "pop-up information" made me impatient. \\
\hline 11 & It was fun to receive such "pop-up information." \\
\hline
\end{tabular}

